\section{EXPANDED CIRCULATING REGULATORY T-CELLS IN VERY LOW BIRTH WEIGHT NEONATES: A MECHANISM FOR TOLERANCE OR A THREAT FOR SEPSIS?}

S. Sánchez-Ramón ${ }^{1}$, M. Cianchetta Sívori ${ }^{1}$, E. Zamora ${ }^{2}$, E. Maderuelo ${ }^{2}$, S. Villar², B. Alonso', B. Padilla ${ }^{3}$, M. Sánchez-Luna ${ }^{2}$

${ }^{1} /$ mmunology, ${ }^{2}$ Neonatology, ${ }^{3}$ Microbiology, Hospital General Universitario Gregorio Marañon, Madrid, Spain

Nosocomial sepsis in very low birth weight (VLBW) infants remains a major problem causing morbidity and mortality. Thus, the search of predictive markers for neonatal sepsis is mandatory. Regulatory T-cells (Treg) are a specialized thymus-derived T-cell subset involved in self-tolerance and suppression of effector responses.

Objective: To determine clinical and immunological markers predicting risk of nosocomial infection in VLBW.

Materials and methods: Inborn VLBW $(<1,500 \mathrm{~g})$ were studied. Clinical parameters and peripheral blood immunophenotype by multi-parametric flowcytometry (umbilical cord blood, UCB, at 7 days and at 1 month of life) were evaluated.

Results: 37 infants were included. Twenty-five (67\%) infants developed nosocomial sepsis (day of onset, $9.9 \pm 3.4)$, and 3 died (12\%). The only statistically significant clinical marker predictive of sepsis was gestational age, $(p=0.005)$. No differences were observed in naïve, memory, pre-effector and/or effector CD4+ T-cells between those who developed sepsis and those who did not. In contrast, VLBW that developed sepsis exhibited higher Treg proportions (CD4+CD25+hi and CD4+CD25+FoxP3+) than those who not at birth $(\mathrm{UCB}, \mathrm{p}=0.02$ and $\mathrm{p}=0.29$, respectively). A significantly higher expression of perforin on Treg was observed in VLBW that developped sepsis $(\mathrm{p}=0.05)$.

Conclusions: Expanded Treg in VLBW infants may reflect a physiologic developing immune system during tolerance learning. VLBW confront with pathogens and other stimuli at an early phase of thymic learning, which can interfere with effector immune responses against pathogens towards a tolerogenic response, and thus higher susceptibility to sepsis.

\section{CD3+CD4+-LYMPHOCYTES AS BIOMARKER PREDICTING THE OUTCOME OF PEDIATRIC HAEMATOPOIETIC STEM CELL TRANSPLANTATION RECIPIENTS}

I. Bartelink', S.V. Belitser', C.A.J. Knibbe ${ }^{3,4}$, M. Danhof ${ }^{4}$, P.J. de Pagter ${ }^{5}$, A.C.G. Egberts ${ }^{2}$, J.J. Boelens ${ }^{5}$

${ }^{1}$ Clinical Pharmacy, UMC Utrecht, ${ }^{2}$ Epidemiology, University of Utrecht, Utrecht, ${ }^{3}$ Clinical Pharmacy, St. Antonius, Nieuwegein, ${ }^{4}$ Pharmacology, Leiden/Amsterdams Center of Drug Research, Leiden University, Leiden, ${ }^{5}$ BMT Unit and Clinical Paediatric Immunology, UMC Utrecht, Utrecht, The Netherlands

Introduction: Haematopoietic stem cell transplantation (HSCT) may be complicated by severe infectious complications, graft-versus-host disease (GvHD) and relapse/graft failures depending on the lymphocyte immune reconstitution. The goal of this study was to identify biomarkers of immunereconstitution that may predict outcome in the first three months after transplant.

Methods: All children transplanted between 20052007 within the UMCU were prospectively included in this study. Immunophenotyping was performed every two weeks after HSCT. In this study we analyzed several parameters of immunereconstitution: AUC, the time and maximum $\mathrm{CD} 3+\mathrm{CD} 4+, \mathrm{CD} 3+\mathrm{CD} 8+$ T-cell and CD19+B-cell numbers, the ratio between CD4/CD8 and the relationship between naive and memory cells in relation with survival, acute- and chronic-GvHD. We focused on the age-related differences of the immune system and donor sources. We used a multiplicative intensity model in $\mathrm{R}$.

Results: 56 recipients received bone marrow, 12 received a sibling donor, while 26 patients received cord blood derived stem cells. The median age at HSCT was 5.9 years (range $0.11-18.1$ ). The logAUC of CD4+ cells in the first 3 months after HSCT positively predicted survival $(P<0.001, H R 0.68$, CI95\% 0.55-0.85.

Conclusion: The AUC of the number of CD4+ cells, 0-90 days after HSCT, predicted long term outcome after HSCT. A low number of CD4 cells (an AUC of approximately 2000 cells*days) in the first period (<3mths) after HSCT predicted poor survival. Both in future studies and in clinical practice this biomarker may be used to predict outcome early after transplantation. 